\title{
Differential expression in histologically normal crypts of ulcerative colitis suggests primary crypt disorder
}

\author{
MIJUNG KIM ${ }^{1}$, SEUNGKOO LEE ${ }^{1}$, SUK-KYUN YANG ${ }^{2}$, KYUYOUNG SONG $^{3}$ and INCHUL LEE ${ }^{1}$ \\ Departments of ${ }^{1}$ Pathology, ${ }^{2}$ Internal Medicine, and ${ }^{3}$ Biochemistry and Molecular Biology, \\ Asan Medical Center, University of Ulsan College of Medicine, Seoul 138-736, Korea
}

Received March 27, 2006; Accepted June 9, 2006

\begin{abstract}
Ulcerative colitis is characterized by crypt infiltration particularly of neutrophils. However, it is not known whether it reflects a primary crypt disorder or a secondary inflammatory response. In this study, we analyzed the expression profiles of histologically normal crypts microdissected from formalin-fixed biopsies of early stage ulcerative colitis. Total RNAs were extracted, amplified, and applied to Affymetrix GeneChip ${ }^{\circledR}$ X3P Array. For the control, similar crypts from nonspecific colitis biopsies were applied. A total of $353(4.3 \%)$ and $111(1.4 \%)$ genes were $>3$ times up-, and down-regulated in ulcerative colitis. Up-regulated genes included FCGBP (Fc fragment of $\mathrm{IgG}$ binding protein), cyclophilin A, chemokine (C-X-C motif) ligand 3, and genes associated with lipid metabolism. Down-regulated genes included APOA4 (apolipoprotein A-IV), cylindromatosis, BCL2-like 10 , claudin 8 , and numerous transcriptional regulators. FCGBP and $A P O A 4$ have been implicated in ulcerative colitis previously. Our data show differential expression in the crypt epithelia of ulcerative colitis before active inflammation is initiated, suggesting primary crypt abnormalities that might be implicated in the pathogenesis of ulcerative colitis.
\end{abstract}

\section{Introduction}

Ulcerative colitis is a chronic inflammatory bowel disease of unknown pathogenesis (1). Diverse genetic backgrounds and aberrant immune regulations have been associated with ulcerative colitis (2). Ulcerative colitis consists of mucosal inflammation with characteristic crypt abscesses (3-8). The infiltration of neutrophils has been taken as a parameter of disease activity (9-12).

Correspondence to: Dr Inchul Lee, Department of Pathology, Asan Medical Center, University of Ulsan College of Medicine, 388-1 Poongnap-Dong, Songpa-Gu, Seoul 138-736, Korea

E-mail: iclee@amc.seoul.kr

Key words: ulcerative colitis, primary crypt disorder, DNA microarray, microdissection, cyclophilin A
In ulcerative colitis, neutrophils appear to infiltrate specifically into the crypts, suggesting that they might target the crypt epithelium. It is particularly evident in early stage biopsies, often showing scattered crypt infiltrates in otherwise unremarkable mucosa. The crypt targeted infiltration is consistent with previous studies of impaired crypt epithelial barriers in ulcerative colitis $(13,14)$. However, it is not clear whether the barrier disruption is a primary disorder or secondary to inflammation (15). Inflammatory cytokines have been shown to down-regulate tight junction proteins secondarily $(16,17)$. Thus, a critical question remains whether the crypt epithelia have pre-existing abnormalities before active infiltration and/or regenerative changes occur.

Expression profiling analyses have reported candidate genes which might be associated with ulcerative colitis (18-25). However, DNA microarray data using whole tissue samples of gastrointestinal tracts is difficult to interpret because of considerable noise from various inflammatory infiltration, stromal reaction, and regenerative epithelial change (26). Recently, a few studies of expression profiling or pattern analysis of isolated inflammatory cells have been reported $(27,28)$. However, no crypt-specific expression profiling has been reported in ulcerative colitis.

Colonoscopic biopsies are routinely fixed in formalin and processed for histopathologic examination. Formalin-fixation provides excellent preparations for the recognition of subtle pathologic changes of crypt epithelium. Furthermore, it would make retrospective studies possible using remnant paraffin blocks in pathology files. However, it causes extensive base modification of nucleic acids (29), which makes it difficult to recover RNAs for expression profiling. The emerging technology has improved considerably the expression profiling of formalin-fixed tissue samples $(30,31)$. Recently, we reported a simple and reproducible procedure of RNA extraction and amplification which successfully detected sequential expression changes in the gastric adenoma/ carcinoma sequence (32).

In this study, we analyzed the expression profiles of histopathologically normal crypts microdissected from formalinfixed, paraffin-embedded biopsies of ulcerative colitis, and a comparison was made with the controls of similar normal crypts in non-specific colitis. Our data show considerable differential expression suggesting that aberrant crypt regulation is implicated in the pathogenesis of ulcerative colitis. 


\section{Materials and methods}

Patients and biopsies. Three biopsies of ulcerative colitis were selected following guidelines of the Institutional Review Board of Asan Medical Center, Seoul, Korea. They were from a 34year-old female and 46-, and 55-year-old male patients who were either first diagnosed as having ulcerative colitis or examined for recurrent clinical symptoms. Clinical and laboratory diagnostic criteria for ulcerative colitis were met in all cases as follows (33): i) a typical history of diarrhea or blood and pus, or both, in the stool for longer than 4 weeks; ii) a typical colonoscopic picture with diffusely granular, friable, or ulcerated mucosa without rectal sparing or skip lesions. Biopsies were diagnostic of ulcerative colitis of early stage showing typical crypt abscesses in mild chronic inflammation. No crypt distortion or regenerative change was evident. For the control, 3 biopsies of nonspecific colitis showing mild inflammation of similar degree were selected. Biopsies were taken from 31-, 49-, and 53-year-old males who had abdominal discomfort and intermittent diarrhea, which did not meet the above criteria. No specific colonoscopic features of ulcerative colitis were present.

Microdissection of crypts. Biopses were fixed immediately in $10 \%$ buffered-formalin and routinely processed for paraffinembedding. After pathological examinations, additional step sections of $8-\mu \mathrm{m}$ thickness were prepared. To avoid RNase contamination, slides and instruments were autoclaved and all solutions were freshly made using DEPC-treated water. From each biopsy, 100 histologically normal crypts were microdissected using the AutoPix laser capture microscope system (Arcturus Bioscience, Inc., Mountain View, CA), as described previously (32). No inflammatory cells were included. To ensure the quality of RNA samples and minimize individual variations, microdissected samples of ulcerative colitis and controls were pooled respectively.

RNA extraction. Microdissected samples were suspended in $200 \mu \mathrm{l}$ digestion buffer [2\% SDS, $10 \mathrm{mM}$ Tris- $\mathrm{HCl}$ (pH 8.0), $0.1 \mathrm{mM}$ EDTA], and incubated at $70^{\circ} \mathrm{C}$ for $1 \mathrm{~h}$ to relieve the formalin-induced modifications. Then, $3 \mu 1$ proteinase $\mathrm{K}$ (30 $\mu \mathrm{g} / \mu 1$, Intron Biotech., Songnam, Korea) was added, and incubated again at $55^{\circ} \mathrm{C}$ for $1 \mathrm{~h}$. RNAs were extracted twice using TRIzol reagents (Invitrogen, Carlsbad, CA) according to the manufacturer's instructions. The extracted RNAs were precipitated in isopropanol with $5 \mu \mathrm{g}$ linear acrylamide (Ambion, Austin, TX), and the RNA pellets were resuspended in $10 \mu 1$ nuclease-free water (Ambion). The quality of extracted RNAs was checked using denaturing agarose gel. The amount of extracted RNA samples and/or amplified RNA was measured using RiboGreen RNA quantitation kit (Molecular probes, Eugene, OR) according to the manufacturer's protocol. Each measurement was duplicated, and the average values were taken.

Affymetrix GeneChip analysis. Amplifications were performed using Affymetrix two-cycle cDNA synthesis kit (Affymetrix, Santa Clara, CA) according to the manufacturer's instructions. To synthesize the first-strand cDNA, 15 ng total RNA was incubated with T7-oligo(dT) primer and SuperScript II reverse transcriptase at $42^{\circ} \mathrm{C}$ for $1 \mathrm{~h}$. After incubating the mixture at $70^{\circ} \mathrm{C}$ for $10 \mathrm{~min}$, E. coli DNA polymerase I and RNase $\mathrm{H}$ were added and incubated at $16^{\circ} \mathrm{C}$ for $2 \mathrm{~h}$ to produce the second-strand cDNAs. First-cycle cRNA synthesis was made by MEGAscript T7 kit (Ambion) by incubating the sample with reagents at $37^{\circ} \mathrm{C}$ for $16 \mathrm{~h}$. cRNAs were purified by GeneChip cleanup module (Affymetrix) according to manufacturer's instructions. Purified cRNAs were used for the second-cycle cDNA synthesis. After the incubation with random primer and SuperScript II at $42^{\circ} \mathrm{C}$ for $1 \mathrm{~h}$, RNase $\mathrm{H}$ was added to the mixture and incubated at $37^{\circ} \mathrm{C}$ for $20 \mathrm{~min}$ additionally. E. coli DNA polymerase I was added and incubated at $16^{\circ} \mathrm{C}$ for $2 \mathrm{~h}$. Then, T4 DNA polymerase was added and incubated at $16^{\circ} \mathrm{C}$ for an additional $10 \mathrm{~min}$.

Purified cDNAs were used for the subsequent in vitro transcription (IVT) labeling reaction using GeneChip IVT labeling kit (Affymetrix) according to manufacturer's instruction. cRNAs were fragmented by incubation at $94^{\circ} \mathrm{C}$ for $35 \mathrm{~min}$. Fragmented cRNAs were hybridized to Affymetrix GeneChip ${ }^{\circledR}$ Human X3P Array at $45^{\circ} \mathrm{C}$ for $16 \mathrm{~h}$. Washing and staining the array was performed by GeneChip Fluidics 450 according to the manufacturer's instructions. Scanning of the array was done using Affymetrix GeneChip Scanner 3000. Expression signals were analyzed using Affymetrix GeneChip software MAS5.0 and Microsoft Excel (Microsoft Corp., Redmond, WA). The complete data set is publicly available in the NCBI Gene Expression Omnibus (http://www.ncbi. nlm.nih.gov/geo/) through the accession number: GSE3801.

Immunohistochemistry. Five ulcerative colitis and control biopsies were immunostained as described previously (34). Immunohistochemical staining was done using a Benchmark Autostainer (Ventana Medical Systems Inc., Tucson, AZ), according to manufacturer's instructions. For the antigen retrieval, slides were heated at $100^{\circ} \mathrm{C}$ for $30 \mathrm{~min}$. Rabbit polyclonal anti-cyclophilin A (Santa Cruz Biotechnology, Santa Cruz, CA) was applied at the dilution of 1:100. The ABC complex was developed using diaminobenzidine as chromogen, and the slides were counterstained with hematoxylin.

\section{Results}

Histopathology and microdissection. Mucosal biopsies of ulcerative colitis showed typical pathologic features with scattered crypt abscesses with epithelial damage (Fig. 1A). However, adjacent uninvolved crypts did not show infiltration or regenerative change (Fig. 1B). In nonspecific colitis, no crypt abscess was present. There were minimal chronic inflammatory infiltration in lamina propria of both ulcerative colitis and nonspecific colitis control. Histopathologically normal crypts were microdissected from ulcerative colitis (Fig. 1C and D); they were indistinguishable from those of nonspecific colitis (Fig. 1E and F). No inflammatory cells were included in the microdissected crypts.

RNA extraction and amplification. From total 300 crypts of ulcerative colitis crypts and controls, 81 and $89 \mathrm{ng}$ total RNAs were extracted, respectively, then $15 \mathrm{ng}$ RNA was applied to the amplification as described in Materials and methods, yielding 7.4 and $6.9 \mu \mathrm{g}$ of aRNA for ulcerative 

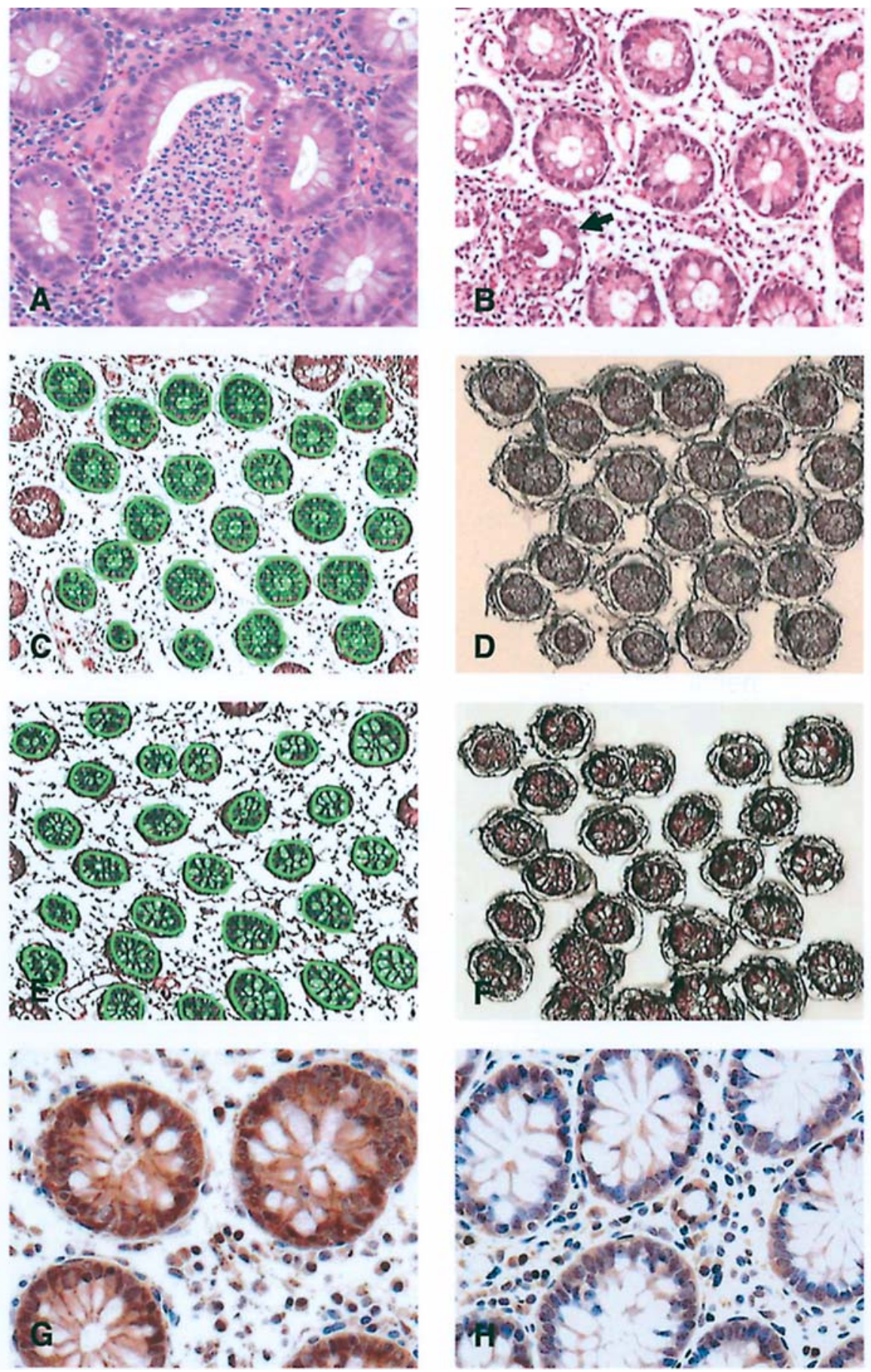

Figure 1. (A) Ulcerative colitis. A typical crypt abscess with dense inflammatory infiltration and epithelial damage is shown (H\&E, x150). (B) Preparation for microdissection without cover slip. A small crypt abscess is recognized (arrow), but adjacent crypts are histologically normal without infiltration or reactive change (H\&E, x100). (C) Histopathologically normal crypts in ulcerative colitis under the laser capture microscope. Crypts to be captured are marked by green circles (x50). (D) Microdissected crypts. Ruffles around crypts reflect capture membranes melted by laser beam (x50). (E) Crypts in nonspecific colitis before microdissection (x50). (F) Microdissected crypts from E, histopathologically indistinguishable from D. (G) Strong immunostaining for cyclophilin A in crypts of ulcerative colitis. Chronic inflammatory cells are similarly immunostained in G and H (ABC method, x200). (H) Nonspecific colitis showing mild immunostaining for cyclophilin A in crypt epithelium (x200).

colitis and control, respectively. For the expression profiling, labeled aRNAs were applied to Affymetrix GeneChip Human X3P Arrays.

DNA microarray analysis. Affymetrix GeneChip Human X3P Array was specifically designed for whole-genome expression profiling of formalin-fixed, paraffin-embedded samples. To detect amplified signals efficiently, the majority of probe sets on the arrays were selected from the 300 bases at the extreme 3 '-end of the transcripts.

Among 61,359 gene spots in the microarray, 14,429 $(23.5 \%)$ and $10,036(16.4 \%)$ spots were hybridized significantly for ulcerative colitis and control, respectively (detection $\mathrm{p}<0.05)$. A total of 8,198 gene spots $(13.4 \%)$ was hybridized significantly in both ulcerative colitis and controls. After sorting out redundant spots for a given gene, 353 (4.3\%) and 
Table I. Up-regulated genes in ulcerative colitis.

\begin{tabular}{|c|c|c|c|c|c|}
\hline Rank & Symbol & Gene title & GenBank ID & Unigene ID & Ratio \\
\hline 1 & XIST & $\mathrm{X}$ (inactive)-specific transcript & NR_001564 & Hs.529901 & 55.525 \\
\hline 2 & CLCA1 & Chloride channel, calcium activated, family member 1 & NM_001285 & Hs. 194659 & 18.931 \\
\hline 3 & - & EST & AK129631 & Hs.433995 & 17.823 \\
\hline 4 & HIST1H4C & Histone $1, \mathrm{H} 4 \mathrm{c}$ & NM_003542 & Hs.46423 & 11.709 \\
\hline 5 & FCGBP & Fc fragment of IgG binding protein & NM_003890 & Hs.111732 & 10.798 \\
\hline 6 & ACTG1 & Actin $\gamma-1$ & NM_001614 & Hs.514581 & 9.425 \\
\hline 7 & MS4A12 & Membrane-spanning 4-domains, subfamily A, member 12 & NM_017716 & Hs.272789 & 9.365 \\
\hline 8 & SLC25A5 & Solute carrier family 25 , member 5 & NM_001152 & Hs.522767 & 9.015 \\
\hline 9 & CXCL3 & Chemokine (C-X-C motif) ligand 3 & NM_002090 & Hs.89690 & 8.992 \\
\hline 10 & PDIA4 & Protein disulfide isomerase family A, member 4 & NM_004911 & Hs.93659 & 8.284 \\
\hline 11 & CEACAM7 & Carcinoembryonic antigen-related cell adhesion molecule 7 & NM_006890 & Hs.74466 & 7.754 \\
\hline 12 & IFITM3 & Interferon induced transmembrane protein $3(1-8 \mathrm{U})$ & NM_021034 & Hs. 374650 & 7.475 \\
\hline 13 & PLAC8 & Placenta-specific 8 & NM_016619 & Hs.546392 & 7.397 \\
\hline 14 & SNRPG & Small nuclear ribonucleoprotein polypeptide G & NM_003096 & Hs.6454 & 7.333 \\
\hline 15 & IFI27 & Interferon, $\alpha$-inducible protein 27 & NM_005532 & Hs.532634 & 7.262 \\
\hline 16 & SFRS10 & Splicing factor, arginine/serine-rich 10 & NM_004593 & Hs.533122 & 7.246 \\
\hline 17 & PSMA7 & Proteasome (prosome, macropain) subunit, $\alpha$ type, 7 & NM_002792 & Hs.233952 & 7.075 \\
\hline 18 & RHOT1 & Ras homolog gene family, member $\mathrm{T} 1$ & NM_018307 & Hs.462742 & 7.004 \\
\hline 19 & FGFBP1 & Fibroblast growth factor binding protein 1 & NM_005130 & Hs. 1690 & 6.945 \\
\hline 20 & PDE8A & Phosphodiesterase 8A & NM_002605 & Hs.306330 & 6.885 \\
\hline 21 & SIPA1L3 & Signal-induced proliferation-associated 1 like 3 & NM_015073 & Hs.157259 & 6.596 \\
\hline 22 & HECTD1 & HECT domain containing 1 & NM_015382 & Hs. 210850 & 6.579 \\
\hline 23 & CEACAM6 & Carcinoembryonic antigen-related cell adhesionmolecule 6 & NM_002483 & Hs.73848 & 6.522 \\
\hline 24 & ZG16 & Zymogen granule protein 16 & NM_152338 & Hs. 184507 & 6.347 \\
\hline 25 & TSPAN3 & Tetraspan 3 & NM_005724 & Hs. 100090 & 6.335 \\
\hline 26 & $\mathrm{CDH} 1$ & Cadherin 1, type 1, E-cadherin (epithelial) & NM_004360 & Hs.194657 & 6.329 \\
\hline 27 & S100A6 & S100 calcium-binding protein A6 & NM_014624 & Hs.275243 & 6.287 \\
\hline 28 & FDFT1 & Famesyl-diphosphate farnesyltransferase 1 & NM_004462 & Hs.546253 & 6.191 \\
\hline 29 & THRAP2 & Thyroid hormone receptor associated protein 2 & NM_015335 & Hs.4084 & 6.175 \\
\hline 30 & LOC389765 & Similar to KIF27C & XM_372122 & Hs. 160561 & 6.093 \\
\hline 31 & ACSL3 & Acyl-CoA synthetase long-chain family member 3 & NM_004457 & Hs. 471461 & 6.055 \\
\hline 32 & HK2 & Hexokinase 2 & NM_000189 & Hs.198427 & 6.047 \\
\hline 33 & ZWINT & ZW10 interactor & NM_007057 & Hs. 42650 & 6.006 \\
\hline 34 & SFPQ & Splicing factor proline/glutamine-rich & NM_005066 & Hs.355934 & 5.993 \\
\hline 35 & ZNF562 & Zinc finger protein 562 & NM_017656 & Hs.531179 & 5.972 \\
\hline 36 & SRP14 & Signal recognition particle $14 \mathrm{kDa}$ & NM_003134 & Hs.533732 & 5.946 \\
\hline 37 & S100A14 & 8100-type calcium binding protein A14 & NM_020672 & Hs. 288998 & 5.936 \\
\hline 38 & C7orf24 & Chromosome 7 open reading frame 24 & NM_024051 & Hs.288649 & 5.845 \\
\hline 39 & HDHD1A & Haloacid dehalogenase-like hydrolase domain containing $1 \mathrm{~A}$ & NM_012080 & Hs.226469 & 5.802 \\
\hline 40 & SUM02 & SMT3 suppressor of mif two 3 homolog 2 (yeast) & NM_006937 & Hs.380973 & 5.770 \\
\hline 41 & SNRPE & Small nuclear ribonucleoprotein polypeptide $\mathrm{E}$ & NM_003094 & Hs.334612 & 5.697 \\
\hline 42 & TARDBP & TAR DNA binding protein & NM_007375 & Hs.300624 & 5.598 \\
\hline 43 & C10orf45 & Chromosome 10 open reading frame 45 & NM_031453 & Hs. 103378 & 5.569 \\
\hline 44 & TSPAN8 & Tetraspanin 8 & NM_004616 & Hs.170563 & 5.567 \\
\hline
\end{tabular}


Table I. Continued.

\begin{tabular}{|c|c|c|c|c|c|}
\hline Rank & Symbol & Gene title & GenBank ID & Unigene ID & Ratio \\
\hline 45 & GALNT2 & $\begin{array}{l}\text { UDP-N-acetyl- } \alpha \text {-D-galactosamine: polypeptide } \\
\text { N-acetylgalactosaminyltransferase } 2 \text { (GalNAc-T2) }\end{array}$ & NM_004481 & Hs. 130181 & 5.531 \\
\hline 46 & SRP9 & Signal recognition particle $9 \mathrm{kD}$ & NM_003133 & Hs. 511425 & 5.439 \\
\hline 47 & FEN1 & Flap structure-specific endonuclease 1 & NM_004111 & Hs. 4756 & 5.401 \\
\hline 48 & VPS35 & Vacuolar protein sorting 35 (yeast) & NM_018206 & Hs. 447547 & 5.398 \\
\hline 49 & $\mathrm{CCT} 2$ & Chaperonin containing TCP1, subunit 2 ( $($ ) & NM_006431 & Hs.6456 & 5.374 \\
\hline 50 & TOP2B & Topoisomerase (DNA) IIß $180 \mathrm{kDa}$ & NM_001068 & Hs.75248 & 5.295 \\
\hline
\end{tabular}

$111(1.4 \%)$ genes were $>3$ times up-, and down-regulated in ulcerative colitis (Tables I and II).

Among up-regulated genes, the top was X (inactive)specific transcript (XIST) (Table I). XIST is expressed only in inactive $\mathrm{X}$ chromosomes, indicating a female origin (35). There was a female patient included in our ulcerative colitis group, while the control group consisted of only males. Thus, the 'up-regulation' of XIST served as an internal control in this study.

Some normally expressed genes in colon were up-regulated considerably: chloride channel calcium activated family member 1 (CLCA1), Fc fragment of IgG binding protein (FCGBP), $\gamma$-actin (ACTG1), trefoil factor 3 (TFF3), carcinoembryonic antigen-related cell adhesion molecule 7 (CEACAM7), and annexin 4 (ANXA4). FCGBP has been reported to be up-regulated in ulcerative colitis (36). It is a mucin-like, non-Fc receptor protein which was implicated in immunological defense of mucosa (37). Annexin 4 is expressed by only epithelial cells.

Genes implicated in inflammation were up-regulated: peptidylprolyl isomerase A (cyclophilin A) (PPIA), nuclear factor of $\kappa$ light polypeptide gene enhancer in B-cells inhibitor $\alpha(\mathrm{NF \kappa} B I \alpha)$, chemokine (C-X-C motif) ligand 3 (CXCL3), CXCL1, and CXCL2. Cyclophilin A has been reported to be a chemotactic factor for neutrophils $(38,39)$. The up-regulation suggested an implication in the neutrophildominant targeted crypt infiltration in ulcerative colitis.

Many lipid metabolism-associated genes were also upregulated: Farnesyl-diphosphate farnesyltransferase 1 (FDFT1), acyl-CoA synthetase long-chain family member 3 (ACSL3), fatty acid binding protein 1, liver (FABP1), low density lipoprotein receptor (LDLR), and fatty acid binding protein 5 (FABP5). Anti-apoptotic genes baculoviral IAP repeat-containing 6 (BIRC6) and ADP-ribosylation factorlike 6 interacting protein (ARL6IP), and cell junction/ cytoskeleton genes E-cadherin (CDH1), tight junction protein 2 (TJP2), and keratin 20 (KRT20) were also up-regulated.

Down-regulated genes included the ones implicated in lipid metabolism such as apolipoprotein A-IV(APOA4) and membrane-bound transcription factor protease site 1 (MBTPS1) (Table II). APOA4 has been implicated in the protection against inflammatory bowel disease in mice suggesting an anti-inflammatory role. Vowinkel et al reported that APOA4-knockout mice were susceptible to experimentally induced colitis, which was protected by exogenous administration of APOA4 (40). Cylindromatosis (CYLD) negatively regulates $\mathrm{NF}_{-} \mathrm{\kappa B}$ signaling by deubiquitination (41). Downregulation of CYLD might also be implicated in enhanced inflammation. Tight junction protein claudin 8 was downregulated, suggesting an implication in the crypt epithelial barriers in ulcerative colitis. Apoptosis-related genes, APG12 autophagy 12-like (APG12L), BCL2-like 10 (BCL2L10) were also down-regulated.

Immunohistochemistry. We investigated the expression of cyclophilin A using immunohistochemistry. In nonspecific colitis control, crypts in the basal compartment were mildly immunostained for cyclophilin A (Fig. 1G). Under the same staining conditions, crypt epithelial cells were strongly immunostained in ulcerative colitis $($ Fig. 1H), concurring with the expression data. Goblet cells were not immunostained. Chronic inflammatory cells were immuno-stained similarly in ulcerative and nonspecific colitis.

\section{Discussion}

We have shown differential expressions in the crypts of ulcerative colitis before the infiltration. We were able to obtain reliable gene expression profiling of microdissected crypts from formalin-fixed, paraffin-embedded tissue using a relatively simple procedure. Our RNA extraction method including sequential heating and proteinase $\mathrm{K}$ digestion has been shown to provide quality samples for DNA microarray analysis (32). Results are significantly better in terms of the amount and quality of amplified signals than the ones, for instance, obtained using a commercially available Paradise ${ }^{\mathrm{TM}}$ Reagent System (Arcturus Bioscience) which is proposed for the application to formalin-fixed, paraffin-embedded tissue (Lee I, et al, unpublished data). Using our method, 100 cross-sectioned crypts were enough to provide RNA for the hybridization to a microarray.

Because morphologically normal crypts from early stage ulcerative colitis were microdissected from well-prepared sections, data noise from inflammatory cell contamination and/ or secondary regenerative epithelial changes were largely eliminated. Mitoses in crypts were minimal in both ulcerative colitis and control, suggesting that nonspecific expressions related to cell proliferation were virtually excluded. The control 
Table II. Down-regulated genes in ulcerative colitis.

\begin{tabular}{|c|c|c|c|c|c|}
\hline Rank & Symbol & Gene title & GenBank ID & Unigene ID & Ratio \\
\hline 1 & & EST & AK097792 & Hs. 518244 & 0.085 \\
\hline 2 & & EST & R98018 & Hs.35533 & 0.088 \\
\hline 3 & HLA-C & Major histocompatibility complex, class I, C & NM_002117 & Hs. 277477 & 0.101 \\
\hline 4 & RNPC3 & RNA-binding region (RNP1, RRM) containing 3 & NM_017619 & Hs.512635 & 0.112 \\
\hline 5 & LOC51315 & Hypothetical protein LOC51315 & NM_016618 & Hs.469254 & 0.120 \\
\hline 6 & APG12L & APG12 autophagy 12-like (S. cerevisiae) & NM_004707 & Hs. 264482 & 0.121 \\
\hline 7 & & EST & ВC033966 & Hs.2.271478.1 & 0.126 \\
\hline 8 & FM05 & Flavin containing monooxygenase 5 & NM_001461 & Hs.303476 & 0.141 \\
\hline 9 & VPS13C & Vacuolar protein sorting 13C (yeast) & NM_001018088 & Hs. 511668 & 0.158 \\
\hline 10 & $\begin{array}{l}\text { DKFZP586 } \\
\text { A0522 }\end{array}$ & DKFZP586A0522 protein & NM_014033 & Hs.288771 & 0.165 \\
\hline 11 & MBNL1 & Muscleblind-like (Drosophila) & NM_021038 & Hs. 478000 & 0.166 \\
\hline 12 & & EST & $\mathrm{BC} 053686$ & & 0.168 \\
\hline 13 & $\mathrm{CDC} 42$ & Cell division cycle 42 (GTP binding protein, $25 \mathrm{kDa}$ ) & AF086337 & Hs. 384596 & 0.172 \\
\hline 14 & GOSR1 & Golgi SNAP receptor complex member 1 & BC012620 & Hs.8868 & 0.178 \\
\hline 15 & LOC 253039 & Hypothetical protein LOC253039 & BF476087 & Hs. 432834 & 0.183 \\
\hline 16 & FAM55A & Family with sequence similarity 55 , member A & NM_152315 & Hs. 374720 & 0.193 \\
\hline 17 & SLC26A8 & Solute carrier family 26 , member 8 & NM_052961 & Hs.20969 & 0.200 \\
\hline 18 & APOA4 & Apolipoprotein A-IV & NM_000482 & Hs. 1247 & 0.203 \\
\hline 19 & & EST & AI082479 & Hs. 271381 & 0.212 \\
\hline 20 & KIAA1970 & KIAA1970 protein & NM_33451 & Hs.559239 & 0.217 \\
\hline 21 & CYLD & Cylindromatosis (turban tumor syndrome) & NM_015247 & Hs.432993 & 0.223 \\
\hline 22 & HRMT1L1 & HMT1 hnRNP methyltransferase-like 1 (S. cerevisiae) & U79286 & Hs. 235887 & 0.224 \\
\hline 23 & PTPN18 & Protein tyrosine phosphatase, non-receptor type 18 & NM_014369 & Hs.516390 & 0.229 \\
\hline 24 & KIAA0804 & KIAA0804 & NM_001009921 & Hs. 269263 & 0.230 \\
\hline 25 & BCL2L10 & BCL2-like 10 (apoptosis facilitator) & NM_020396 & Hs. 283672 & 0.231 \\
\hline 26 & RNU17D & RNA, U17D small nucleolar & AJ006834 & Hs. 469723 & 0.232 \\
\hline 27 & XKR5 & X Kell blood group precursor-related family, member 5 & NM_207411 & Hs.369771 & 0.233 \\
\hline 28 & NBR1 & Neighbor of BRCA1 gene 1 & NM_005899 & Hs. 277721 & 0.234 \\
\hline 29 & HOXD10 & Homeo boxD10 & AW299531 & Hs. 188023 & 0.236 \\
\hline 30 & CPM & Carboxypeptidase M & NM_001005502 & Hs. 484551 & 0.237 \\
\hline 31 & SNRP70 & Small nuclear ribonucleoprotein $70 \mathrm{kD}$ polypeptide & NM_001009820 & Hs.467097 & 0.243 \\
\hline 32 & HCG18 & HLA complex group 18 & AK056160 & Hs.301985 & 0.243 \\
\hline 33 & SUZ12 & Suppressor of zeste 12 homolog (Drosophila) & NM_015355 & Hs. 462732 & 0.244 \\
\hline 34 & THUMPD3 & THUMP domain containing 3 & NM_015453 & Hs.443081 & 0.249 \\
\hline 35 & RAB11B & RAB11B, member RAS oncogene family & NM_004218 & Hs. 433888 & 0.250 \\
\hline 36 & & EST & AK024994 & Hs.306738 & 0.252 \\
\hline 37 & & EST & ВC020857 & Hs.554307 & 0.254 \\
\hline 38 & ZNF16 & Zinc finger protein 16 (KOX 9) & NM_006958 & Hs.23019 & 0.255 \\
\hline 39 & & EST & AW002073 & Hs. 236524 & 0.257 \\
\hline 40 & C21orf88 & Chromosome 21 open reading frame 88 & AF426267 & Hs. 375120 & 0.261 \\
\hline 41 & & EST & ВC022384 & Hs.352171 & 0.262 \\
\hline 42 & LR8 & LR8 protein & NM_014020 & Hs.521295 & 0.263 \\
\hline 43 & CROP & Cisplatin resistance-associated overexpressed protein & BE887449 & Hs.32112 & 0.265 \\
\hline
\end{tabular}


Table II. Continued.

\begin{tabular}{|c|c|c|c|c|c|}
\hline Rank & Symbol & Gene title & GenBank ID & Unigene ID & Ratio \\
\hline 44 & C19orf33 & Chromosome 19 open reading frame 33 & NM_033520 & Hs. 348553 & 0.268 \\
\hline 45 & & EST & ВC004382 & Hs.267319 & 0.270 \\
\hline 46 & SLC17A4 & Solute carrier family 17 (sodium phosphate), member 4 & NM_005495 & Hs.282931 & 0.270 \\
\hline 47 & SMARCE1 & $\begin{array}{l}\text { SWI/SNF related, matrix associated, actin dependent } \\
\text { regulator of chromatin, subfamily e, member } 1\end{array}$ & NM_003079 & Hs.233354 & 0.271 \\
\hline 48 & FLJ30313 & Hypothetical protein FLJ30313 & NM_152757 & Hs. 444743 & 0.272 \\
\hline 49 & FLJ90396 & Hypothetical protein FLJ90396 & NM_153358 & Hs.346875 & 0.275 \\
\hline 50 & RPS4Y1 & Ribosomal protein S4, Y-linked 1 & NM_001008 & Hs.180911 & 0.277 \\
\hline
\end{tabular}

was taken similarly from nonspecific colitis to eliminate potential effect of 'inflammatory environment' that might not have been reflected morphologically.

For this study, a standard linear amplification method was adopted using an Affymetrix kit. However, the procedure including two-cycle amplification would inevitably induce deviation of data the extent of which is not clear in this study. Nevertheless, there is evidence that support the reliability of our data. The fact that female-origin XIST was the most upregulated gene strongly suggests the fidelity of our data serving as an internal control. The immunohistochemical staining of cyclophilin A also supported the expression data. Among the differentially expressed genes, those being implicated in ulcerative colitis such as APOA4 and FCGBP were included. Another indirect evidence of the reproducibility is the redundancy of signals. In the microarray, some genes are represented by redundant spots in which seeded oligonucleotides are not necessarily identical. For instance, $10 \gamma$-actin and 6 cyclophilin A spots were included in the differential expression, suggesting the reproducibility. Together, it is suggested that reliable expression profiling data could be obtained using a reasonable number of microdissected cells from routinely processed biopsies, although there is considerable loss of signals in quantity. The amount of data obtained from formalin-fixed biopsies appear to be reduced to about half of the fresh sample counterparts using our procedure (Lee I, et al, unpublished data). The obtainable data may be extended by increasing the load and/or repeated applications.

The up-regulation of cyclophilin A in normal crypts might suggest an implication in the pathogenesis. Cyclophilin A is an intracellular protein that is known as a receptor for the immunosuppressive drug, cyclosporine A $(38,39)$. Cyclophilin A is elevated in inflammation and may induce neutrophil chemotaxis in vivo and in vitro. The neutrophil chemotaxis concurs with the crypt-specific infiltration in ulcerative colitis. The pathobiological role of Cyclophilin A and other inflammation-associated genes needs further characterization in ulcerative colitis.

Numerous genes associated with lipid metabolism were differentially expressed, suggesting a pathogenic association of aberrant lipid regulation with ulcerative colitis. It has been shown that APOA4 has a protective effect against experimentally induced inflammatory bowel disease in mice (40). The up-regulation of FABP1 was concurrent with a previous expression profiling study (20).

Down-regulation of claudin 8 might be consistent with previous studies of altered epithelial barriers of colonic mucosa in ulcerative colitis (13-15). Claudin 8 is a member of a large family of tight junction integral membrane protein, and is suggested to have a cation barrier function (42). In our data, claudins 4,12 , and 15 were not differentially expressed, and claudin 7 was up-regulated $<3$ times. Other claudins were not significantly hybridized. Tight junction protein 2 (zona occludens 2) and adherent junction protein E-cadherin were up-regulated. It is possible that only a limited number of tight junction protein(s) might be down-regulated in ulcerative colitis while other junction proteins show compensatory up-regulation.

Taken together, the differential expression in uninflamed crypt epithelia suggests innate disorders of crypt regulation in ulcerative colitis. Differentially expressed genes of various functions might suggest a complex pathogenesis encompassing abnormal epithelial barrier and aberrant immune regulation (Kim et al, unpublished data). As diagnostic biopsies may be applied readily, we expect that the expression profiling will be extended for various purposes such as sequential progression of subtle diseases and treatment effects.

\section{Acknowledgements}

We thank Seol Baik for immunohistochemical staining. This work was supported by a grant from the Basic Research Program of the Korea Science \& Engineering Foundation (R01-2004-000-10670-0).

\section{References}

1. Fiocchi C: Inflammatory bowel disease: etiology and pathogenesis. Gastroenterology 115: 182-205, 1998.

2. Bouma G and Strober W: The immunological and genetic basis of inflammatory bowel disease. Nat Rev Immunol 3: 521-533, 2003.

3. Nostrant TT, Kumar NB and Appelman HD: Histopathology differentiates acute self-limited colitis from ulcerative colitis. Gastroenterology 92: 318-328, 1987.

4. Goldman H: Acute versus chronic colitis: how and when to distinguish by biopsy. Gastroenterology 86: 199-201, 1984. 
5. Seldenrijk CA, Morson BC, Meuwissen SG, Schipper NW, Lindeman $\mathrm{J}$ and Meijer CJ: Histopathological evaluation of colonic mucosal biopsy specimens in chronic inflammatory bowel disease: diagnostic implications. Gut 32: 1514-1520, 1991.

6. Jenkins D, Balsitis M, Gallivan S, Dixon MF, Gilmour HM, Shepherd NA, Theodossi A and Williams GT: Guidelines for the initial biopsy diagnosis of suspected chronic idiopathic inflammatory bowel disease. The British Society of Gastroenterology Initiative. J Clin Pathol 50: 93-105, 1997.

7. Tanaka M, Riddell RH, Saito H, Soma Y, Hidaka H and Kudo H: Morphologic criteria applicable to biopsy specimens for effective distinction of inflammatory bowel disease from other forms of colitis and of Crohn's disease from ulcerative colitis. Scand J Gastroenterol 34: 55-67, 1999.

8. Warren BF: Classic pathology of ulcerative and Crohn's colitis. J Clin Gastroenterol 38 (Suppl 5): S33-S35, 2004.

9. Gomes P, du Boulay C, Smith CL and Holdstock G: Relationship between disease activity indices and colonoscopic findings in patients with colonic inflammatory bowel disease. Gut 27: 92-95, 1986.

10. Ina K, Kusugami K, Yamaguchi T, Imada A, Hosokawa T, Ohsuga M, Shinoda M, Ando T, Ito K and Yokoyama Y: Mucosal interleukin-8 is involved in neutrophil migration and binding to extracellular matrix in inflammatory bowel disease. Am J Gastroenterol 92: 1342-1346, 1997.

11. Elliott SN and Wallace JL: Neutrophil-mediated gastrointestinal injury. Can J Gastroenterol 12: 559-568, 1998

12. Geboes K, Riddell R, Ost A, Jensfelt B, Persson T and Lofberg R: A reproducible grading scale for histological assessment of inflammation in ulcerative colitis. Gut 47: 404-409, 2000.

13. Schmitz H, Barmeyer C, Fromm M, Runkel N, Foss HD, Bentzel CJ, Riecken EO and Schulzke JD: Altered tight junction structure contributes to the impaired epithelial barrier function in ulcerative colitis. Gastroenterology 16: 301-309, 1999.

14. Gassler N, Rohr C, Schneider A, Kartenbeck J, Bach A, Obermuller N, Otto HF and Autschbach F: Inflammatory bowel disease is associated with changes of enterocytic junctions. Am J Physiol Gastrointest Liver Physiol 281: G216-G228, 2001.

15. Kucharzik T, Walsh SV, Chen J, Parkos CA and Nusrat A: Neutrophil transmigration in inflammatory bowel disease is associated with differential expression of epithelial intercellular junction proteins. Am J Pathol 159: 2001-2009, 2001.

16. Bruewer M, Luegering A, Kucharzik T, Parkos CA, Madara JL, Hopkins AM and Nusrat A: Proinflammatory cytokines disrupt epithelial barrier function by apoptosis-independent mechanisms. J Immunol 171: 6164-6172, 2003.

17. Heller F, Florian P, Bojarski C, Richter J, Christ M, Hillenbrand B, Mankertz J, Gitter AH, Burgel N, Fromm M, Zeitz M, Fuss I, Strober W and Schulzke JD: Interleukin-13 is the key effector Th2 cytokine in ulcerative colitis that affects epithelial tight junctions, apoptosis, and cell restitution. Gastroenterology 129: 550-564, 2005.

18. Okahara S, Arimura Y, Yabana T, Kobayashi K, Gotoh A, Motoya S, Imamura A, Endo T and Imai K: Inflammatory gene signature in ulcerative colitis with cDNA macroarray analysis. Aliment Pharmacol Ther 21: 1091-1097, 2005.

19. Langmann T, Moehle C, Mauerer R, Scharl M, Liebisch G, Zahn A, Stremmel W and Schmitz G: Loss of detoxification in inflammatory bowel disease: dysregulation of pregnane $\mathrm{X}$ receptor target genes. Gastroenterology 127: 26-40, 2004.

20. Dooley TP, Curto EV, Reddy SP, Davis RL, Lambert GW, Wilborn TW and Elson CO: Regulation of gene expression in inflammatory bowel disease and correlation with IBD drugs: screening by DNA microarrays. Inflamm Bowel Dis 10: 1-14, 2004.

21. Masuda H, Takahashi Y, Asai S and Takayama T: Distinct gene expression of osteopontin in patients with ulcerative colitis. J Surg Res 111: 85-90, 2003.

22. Dieckgraefe BK, Crimmins DL, Landt V, Houchen C, Anant S, Porche-Sorbet R and Ladenson JH: Expression of the regenerating gene family in inflammatory bowel disease mucosa: Reg I alpha upregulation, processing, and antiapoptotic activity. J Investig Med 50: 421-434, 2002.

23. Uthoff SM, Eichenberger MR, Lewis RK, Fox MP, Hamilton CJ, McAuliffe TL, Grimes HL and Galandiuk S: Identification of candidate genes in ulcerative colitis and Crohn's disease using cDNA array technology. Int J Oncol 19: 803-810, 2001.

24. Lawrance IC, Fiocchi C and Chakravarti S: Ulcerative colitis and Crohn's disease: distinctive gene expression profiles and novel susceptibility candidate genes. Hum Mol Genet 10: 445-456, 2001.
25. Dieckgraefe BK, Stenson WF, Korzenik JR, Swanson PE and Harrington CA: analysis of mucosal gene expression in inflammatory bowel disease by parallel oligonucleotide arrays. Physiol Genomics 4: 1-11, 2000.

26. Kim B, Bang S, Lee S, Kim S, Choi K, Lee C, Lee SG, Lee K, Lee Y, Kim Y, Kim S, Yeom Y, Yu H, Song K and Lee I: Expression profiling and subtype-specific expression of stomach cancer. Cancer Res 63: 8248-8255, 2003.

27. Schreiter K, Hausmann M, Spoettl T, Strauch UG, Bataille F, Schoelmerich J, Herfarth H, Falk W and Rogler G: Glycoprotein (gp) 96 expression: induced during differentiation of intestinal macrophages but impaired in Crohn's disease. Gut 54: 935-943, 2005.

28. Ten Hove T, The Olle F, Berkhout M, Bruggeman JP, Vyth-Dreese FA, Slors JF, Van Deventer SJ and Te Velde AA: Expression of CD45RB functionally distinguishes intestinal $\mathrm{T}$ lymphocytes in inflammatory bowel disease. J Leukoc Biol 75: 1010-1015, 2004.

29. Masuda N, Ohnishi T, Kawamoto S, Monden M and Okubo K: Analysis of chemical modification of RNA from formalin-fixed samples and optimization of molecular biology applications for such samples. Nucleic Acids Res 27: 4436-4443, 1999.

30. Bibikova M, Talantov D, Chudin E, Yeakley JM, Chen J, Doucet D, Wickham E, Atkins D, Barker D, Chee M, Wang Y and Fan JB: Quantitative gene expression profiling in formalinfixed, paraffin-embedded tissues using universal bead arrays. Am J Pathol 165: 1799-1807, 2004.

31. Paik S, Kim CY, Song YK and Kim WS: Technology insight: Application of molecular techniques to formalin-fixed paraffinembedded tissues from breast cancer. Nat Clin Pract Oncol 2: 246-254, 2005.

32. Lee C, Bang S, Lee S, Song K and Lee I: Gene expression profiling reveals sequential change in gastric tubular adenoma and carcinoma in situ. World J Gastroenterol 11: 1937-1945, 2005.

33. Yang SK, Hong WS, Min YI, Kim HY, Yoo JY, Rhee PL, Rhee JC, Chang DK, Song IS, Jung SA, Park EB, Yoo HM, Lee DK and Kim YK: Incidence and prevalence of ulcerative colitis in the Songpa-Kangdong District, Seoul, Korea, 1986-1997. J Gastroenterol Hepatol 15: 1037-1042, 2000.

34. Jang J, Lee S, Jung Y, Song K, Fukumoto M, Gould VE and Lee I: Malgun (clear) cell change in Helicobacter pylori gastritis reflects epithelial genomic damage and repair. Am J Pathol 162: 1203-1211, 2003

35. Vawter MP, Evans S, Choudary P, Meador-Woodruff J, Tomita H, Molnar M, Li J, Lopez JF, Myers R, Cox D, Watson SJ, Akil H, Jones EG and Bunney WE: Gender-specific gene expression in post-mortem human brain: localization to sex chromosomes. Neuropsychopharmacology 29: 373-384, 2004.

36. Kobayashi K, Blaser MJ and Brown WR: Identification of a unique $\mathrm{IgG} \mathrm{Fc}$ binding site in human intestinal epithelium. J Immunol 143: 2567-2574, 1989.

37. Kobayashi K, Ogata H, Morikawa M, Iijima S, Harada N, Yoshida T, Brown WR, Inoue N, Hamada Y, Ishii H, Watanabe M and Hibi T: Distribution and partial characterisation of IgG Fc binding protein in various mucin producing cells and body fluids. Gut 51: 169-176, 2002.

38. Xu Q, Leiva MC, Fischkoff SA, Handschumacher RE and Lyttle CR: Leukocyte chemotactic activity of cyclophilin. J Biol Chem 267: 11968-11971, 1992.

39. Arora K, Gwinn WM, Bower MA, Watson A, Okwumabua I, MacDonald HR, Bukrinsky MI and Constant SL: Extracellular cyclophilins contribute to the regulation of inflammatory responses. J Immunol 175: 517-522, 2005.

40. Vowinkel T, Mori M, Krieglstein CF, Russell J, Saijo F, Bharwani S, Turnage RH, Davidson WS, Tso P, Granger DN and Kalogeris TJ: Apolipoprotein A-IV inhibits experimental colitis. J Clin Invest 114: 260-269, 2004.

41. Trompouki E, Hatzivassiliou E, Tsichritzis T, Farmer H, Ashworth A and Mosialos G: CYLD is a deubiquitinating enzyme that negatively regulates NF-kappa-B activation by TNFR family members. Nature 424: 793-796, 2003.

42. Yu AS, Enck AH, Lencer WI and Schneeberger EE: Claudin-8 expression in Madin-Darby canine kidney cells augments the paracellular barrier to cation permeation. J Biol Chem 278: 17350-17359, 2003. 